Vries, M. de, Weert, J.C.M. van, Jansen, J., Lemmens, E.P.P., Maas, A.A.M. Step by step development of clinjcal care pathways for older cancer patients: necessary or desirable? European Journal of Cancer: 2007,43(15), 2170-2178

\begin{tabular}{|c|c|}
\hline Postprint Version & 1.0 \\
\hline Journal website & http://linkinghub.elsevier.com/retrieve/pii/S0959-8049(07)00615-6 \\
\hline Pubmed link & $\begin{array}{l}\text { http://www.ncbi.nlm.nih.gov/pubmed/17870519?ordinalpos=1\&itool=EntrezSy } \\
\text { stem2.PEntrez.Pubmed.Pubmed_ResultsPanel.Pubmed_RVDocSum }\end{array}$ \\
\hline DOI & 10.1016/j.ejca.2007.08.004 \\
\hline
\end{tabular}

This is a NIVEL certified Post Print, more info at http://www.nivel.eu

\title{
Step by step development of clinical care pathways for older cancer patients: Necessary or desirable?
}

\author{
MARUSCHA DE VRIES ${ }^{\mathrm{A}}$, JULIA C.M. VAN WEERT ${ }^{\mathrm{B}}$, JESSE JANSEN ${ }^{\mathrm{C}}$, VALERY E.P.P. LEMMENS ${ }^{\mathrm{A}, \mathrm{D}}$ AND HUUB \\ A.A.M. MAAS ${ }^{\mathrm{A}, \mathrm{E}}$. \\ a Comprehensive Cancer Centre South, P.O. Box 231, 5600 AE Eindhoven, The Netherlands \\ bThe Amsterdam School of Communications Research (ASCoR), University of Amsterdam, Amsterdam, \\ The Netherlands \\ cNIVEL (Netherlands Institute for Health Services Research), Utrecht, The Netherlands \\ dErasmus University Medical Centre Rotterdam, Rotterdam, The Netherlands \\ eDepartment of Geriatric Medicine, TweeSteden Hospital, Tilburg, The Netherlands
}

\begin{abstract}
Medical and nursing staff in oncology for older cancer patients are confronted with a range of problems including co-morbidity, poly-pharmacy, cognitive impairments, emotional problems, functional limitations, sensory impairment and a lack of social support. Comprehensive geriatric assessment identifies many of the existing problems and can be used to estimate life expectancy and tolerance of treatment. However, health care providers have to interpret and apply the medical and nursing information and must deal with specific problems and care needs throughout the continuum of cancer care. Imperfect interdisciplinary communication, cooperation and patient-provider communication may further complicate the care actually delivered. A clinical care pathway aims to improve continuity, increase multidisciplinary tuning and deliver appropriate patient education, treatment and care for vulnerable older cancer patients. This paper gives an overview of common problems in older cancer patients and addresses communication barriers through the development of clinical care pathways in geriatric oncology.
\end{abstract}

\section{INTRODUCTION}

Cancer incidence increases with age. Within the European Community (EC), approximately one million cases of cancer are diagnosed per year, of which more than $55 \%$ occur in people aged over 65 years. By the year 2020, $60 \%$ of all malignancies will affect this age group. ${ }^{1}$ Older cancer patients often present complex problems that require comprehensive physical and psychosocial support, often provided by multiple professionals working in different health care providing organisations. ${ }^{2}$ Based on the number of patients presenting with one or more co-morbid conditions, approximately $50-75 \%$ of elderly patients are expected to be in need of comprehensive, psychosocial and physical support. To deal with this complexity in everyday practice, several options are proposed in oncology, i.e. implementing comprehensive assessment techniques, the use of frailty-tests or an interdisciplinary oncological-geriatric team. ${ }^{3}$

Another way to deal with complex or interdisciplinary care is to develop a clinical care pathway. The term clinical care pathway is internationally accepted in all health care management settings, although its development differs in the United Kingdom from the USA. A clinical care pathway is a methodology for the mutual decision making and organisation of care for a well-defined group of patients during a welldefined period of time. ${ }^{4}$ The aim of a clinical care pathway is to improve quality of care, reduce risks of 
Vries, M. de, Weert, J.C.M. van, Jansen, J., Lemmens, E.P.P., Maas, A.A.M. Step by step development of clinjical care pathways for older cancer patients: necessary or desirable? European Journal of Cancer: 2007, 43(15), 2170-2178

unintended effects and death, increase patient satisfaction and improve efficiency of resource usage. Characteristics of clinical care pathways include: ${ }^{5}$

- An explicit statement of the goals and key elements of care, not only based on evidence or best practice, but also on patients expectations.

- Improve communication, coordination of roles and sequencing of the activities of the multidisciplinary care team, patients and their relatives.

- Documentation, monitoring, evaluation of variances and outcomes and the identification of appropriate resources. $^{\text {[4], [6] and [7] }}$

The following alternative names to clinical care pathways have been put forward: critical pathway, clinical care pathway, integrated care pathway, care pathway, and care map. ${ }^{8}$

Clinical care pathways are developed by multi-professional teams, composed of all types of physicians (from family practitioners to specialists), nurses, social workers and administrators, who manage the disease processes and are responsible for patient care. ${ }^{9}$

This paper discusses the development of a clinical care pathway focusing on older cancer patients. We discuss the main items which are relevant to interdisciplinary care and argue why these items should be integrated in clinical care pathways.

\section{CLINICAL CARE PATHWAYS AND THEIR ADDED VALUE}

Clinical care pathways are an evidence-based response at both a structured and local level, to specific problems and care needs, and for this reason they would have a higher level of compliance compared with other instruments such as top-down practice guidelines, which are primarily based on science and less on local professional consensus. ${ }^{9}$ The clinical care pathway as a document is not as crucial as the discussion of the entire process of care, to be made explicit in order to be shared by the interdisciplinary team. Since the process is explicit, best practice will have to be discussed, timing and procedures can be planned and scheduled better, desirable outcomes can be set and monitored and capacity and resources can be provided. ${ }^{10}$ In-built continuous evaluation and follow-up should guarantee the effectiveness of a clinical care pathway by measuring quality indicators or outcomes. The use of a Clinical Care Compass is recommended, distinguishing five domains for evaluation: clinical outcome, service, team, process and financial indicators (Fig. 1).

\section{[FIGURE 1]}

A review of the effects of clinical care pathways showed predominantly positive effects in the domains of process, team and resource allocation. ${ }^{6}$ Although clinical care pathways are intended to improve the multidisciplinary teamwork and care, a vast number of pathway projects are only evaluated in economic parameters. Moreover, clinical care pathways without positive results will hardly be published. ${ }^{6}$ The overall purpose of clinical care pathways is to improve outcome by providing a mechanism to coordinate care and to reduce fragmentation, and ultimately cost. ${ }^{9}$

In oncology, studies on clinical care pathways showed improvements in terminally ill patients, e.g. improved symptom management and documentation of treatment plans. ${ }^{11}$ In the financial domain, positive results are also reported in gynaecological oncology. ${ }^{12}$ A review on quality of cancer care, guidelines and clinical care pathways demonstrated improvements in compliance to guidelines and evidence based medicine, length of hospital stay, complications rate and financial costs. However, studies showed divergent results. A patient specific implementation plan and accountability for process and outcomes are key components to a successful programme. ${ }^{13}$ We did not find examples of clinical care pathways for vulnerable older cancer patients in the hospital setting.

\section{CLINICAL CARE PATHWAYS FOR OLDER CANCER PATIENTS}

\subsection{Towards a framework for 'geriatric' clinical care pathways}

Since the early 1990s, oncologists and geriatricians have begun to work together to integrate principles of geriatrics into oncology care, for instance by using a comprehensive geriatric assessment (CGA). ${ }^{14} \mathrm{CGA}$ identifies many of the existing problems in older people with cancer and may improve the prognosis for these patients ${ }^{15}$ and predict morbidity and mortality. ${ }^{14}$ One of the perceived barriers to CGA is the lack of a well-defined procedure to interpret and apply the information it provides. ${ }^{16}$ In oncology, most studies of the CGA do not include interventions based on CGA; CGA is primarily used as a search on 'pre-treatment 
Vries, M. de, Weert, J.C.M. van, Jansen, J., Lemmens, E.P.P., Maas, A.A.M. Step by step development of clinjical care pathways for older cancer patients: necessary or desirable? European Journal of Cancer: 2007, 43(15), 2170-2178

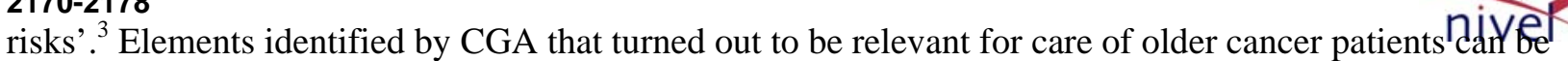
integrated in clinical care pathways. Furthermore, communication skills adapted to the geriatric population can be incorporated in the pathway. A 'geriatric' clinical care pathway provides opportunities to define the care process from diagnosis to end of treatment and to include multidisciplinary interventions.

\subsection{Older cancer patients' characteristics: to define in 'geriatric' clinical care pathways}

Table 1 gives a summary of the main problems of older cancer patients, which should be addressed in clinical care pathways, and their implications. Clinical care pathways should define interventions and agreements to adapt to these problems. The content of the table will be discussed in this paragraph.

\section{[TABLE 1]}

\subsubsection{Co-morbidity and poly-pharmacy}

Older cancer patients are likely to have other chronic disabling conditions (co-morbidity). Table 2 shows the percentages of co-morbidity in older cancer patients affected by the most common tumours. Comorbidity has been associated with treatment intolerance and is an independent predictor of survival in cancer patients. ${ }^{[17] \text { and }[18]}$ The interactions of co-morbidity with complication-rate, survival and disease progression increase with age. ${ }^{19}$ In patients with serious co-morbidity, the physician might therefore decide to alter standard oncological treatment because of increased risk of side-effects or limited life expectancy.

\section{[TABLE 2]}

A consequence of increased co-morbidity is the accompanying co-medication. Poly-pharmacy can lead to drug interactions interfering with cytotoxic agents, and should therefore be considered in terms of treatment decisions. ${ }^{20}$ Assessment of co-morbidity and drug use should be an explicit step that is defined in the clinical care pathway of elderly patients.

\subsubsection{Emotional conditions and social factors}

Studies of psychological distress in older patients with cancer have reported a high prevalence of affective disorders. In a study among lung cancer patients, the prevalence of self-reported depression was $33 \%$ and $39 \%$ for self-reported anxiety. ${ }^{21}$ Depression is one of the most frequently present psychological disorders among older people ${ }^{22}$ and disabled patients are more at risk of developing depression than healthy persons. ${ }^{[21]}$ and ${ }^{[23]}$ Depression affects adherence to treatment plans, ${ }^{[24]}$ and ${ }^{[25]}$ is related to a decreased quality of life ${ }^{[26]}$ and ${ }^{[27]}$ and is an independent prognostic factor for mortality in elderly cancer patients. ${ }^{[28] \text { and }[29]}$ Despite its high prevalence, depression in cancer patients is often underestimated, especially in those who are most depressed. Screening instruments and the use of brief follow-up interviews could help to identify depression in older cancer patients and be a first step in initiating anti-depressive treatment. ${ }^{30}$

Many older cancer patients receive inadequate social support. ${ }^{31}$ Depression is closely related to inadequate social support. ${ }^{32}$ Higher levels of positive social support and psychosocial resources for older breast cancer patients predicted not only better outcomes in terms of depression, but also better life satisfaction and selfperceived physical health (general health perception). ${ }^{33}$ These findings suggest that older cancer patients might benefit from psychosocial interventions aimed at enhancing protective psychosocial resources ${ }^{33}$ and improving social support. ${ }^{32}$ Clinical care programmes should advocate psychosocial assessment techniques and define psychosocial support, especially in depressed patients.

\subsubsection{Malnutrition, functional and sensory impairments}

The prevalence of functional impairments among cancer patients aged 65 years or older increases with age. ${ }^{34}$ Functional decline refers to the ability of the individual to perform activities of daily living (ADL), such as using the toilet, dressing and eating, and to perform instrumental activities of daily living (IADL), such as using transportation, shopping, taking medication and preparing meals. ${ }^{[20]}{ }^{\text {and }[35]}$ ADL dependence among older cancer patients is associated with poor prognosis and life expectancy and IADL dependency with poor tolerance to chemotherapy. ${ }^{[2]}$ and ${ }^{[28]}$ Furthermore, functional decline often determines the ability to return home and requires coordination with home care facilities or other services.

Older individuals are also more vulnerable to nutritional complications, possibly resulting in enhanced toxicity of treatment. Dietary interventions can prevent or reverse malnutrition in older cancer patients. ${ }^{24}$ Sensory impairments are predictive of subsequent functional impairment in older persons, particularly in the case of combined vision and hearing impairments. ${ }^{36}$ Interventions to improve sensory function may also 
Vries, M. de, Weert, J.C.M. van, Jansen, J., Lemmens, E.P.P., Maas, A.A.M. Step by step development of clinjcal care pathways for older cancer patients: necessary or desirable? European Journal of Cancer: 2007, 43(15), 2170-2178

improve functional independence. ${ }^{37}$ Various studies also report a relationship between a decrease nin serésbry functioning and a decrease in cognitive functioning, ${ }^{[38],[39]}{ }^{\text {and }}{ }^{[40]}$ e.g. deterioration in visual or auditory acuity predicted change in memory performance in cognitive performance. ${ }^{40}$ Therefore, it is essential to screen older cancer patients for sensory function, especially to identify changes in visual or auditory acuity that are subsequently responsible for changes in cognition ${ }^{40}$ or functional impairment. In addition, assessment and interventions focussing on (I)ADL and nutrition have to be defined in clinical care pathways.

\subsubsection{Cognitive status and recall of information}

Older people in general experience age-related cognitive changes that affect the processing of medical information, medical compliance and ultimately, medical outcomes. ${ }^{41}$ A literature review reported a prevalence of memory complaints in older people from outpatient or community samples (aged 62-92) ranging from $25 \%$ to $50 \%$. In community-based samples of elderly people, memory complaints predicted dementia after a 2 years or longer follow-up. ${ }^{42}$ Cognitive impairment increases mortality risk ${ }^{28}$ and dementia may be worsened by cytotoxic chemotherapy. ${ }^{24}$ General cognitive decline might also interfere with treatment adherence. ${ }^{41}$ A patient's ability to comprehend and recall several types of medical information is often limited and may affect the optimal use of medical services. ${ }^{41}$ Furthermore, older people process information more slowly than younger ones ${ }^{43}$ and experience a reduction in the capacity to ignore irrelevant information. ${ }^{44}$ Health care providers and clinicians rarely address the issue of age-related cognitive changes when delivering care and particularly information to older patients. ${ }^{45}$ Taking into account cognitive functioning of a patient is essential: both to adapt the provision of information and also the individual treatment plan.

Recall of information is not only determined by cognitive changes; stress and anxiety also lead to difficulties in processing and recalling important information. ${ }^{[4]] \text { and }[47]}$ Remembering information from a medical consultation has been associated with decision making, ${ }^{48}$ treatment compliance ${ }^{[48] \text { and [49] }}$ and patient satisfaction ${ }^{48}$ and is therefore important for patients' health and well-being. In a recent study on the recall of information by cancer patients aged 65 and over, recognition of important treatment information appeared to be satisfactory, but active reproduction was indeed poor (23\% recalled correctly). Active reproduction is essential for treatment compliance. Certain advice, such as how to prevent treatment side effects or how to deal with adverse treatment effects, needs to be retained. ${ }^{50}$ Recall of information by older cancer patients can be improved by targeting the information. This effectively reduces the amount of information, ensures that the information is personally relevant and makes information provision patient-centred and tailored to their needs and abilities. Personal relevance of the information for an individual determines to a large extent whether information will receive attention and if patient-centred instructions result in better understanding by older people, rather than using the standard approach. ${ }^{51}$ Table 3 gives 10 communication tips for older cancer patients, to be included in 'geriatric' clinical care pathways.

\section{[TABLE 3]}

\section{EFFECTIVE COMMUNICATION AND INFORMATION NEEDS}

Health care providers should have the knowledge and skills to communicate effectively with their older patients. Communication is considered to be a vital clinical skill in oncology, ${ }^{[52]}$ and [53] especially for older cancer patients, as they use fewer other sources of information than younger patients and tend to have greater faith in information presented by the medical staff. ${ }^{54}$ However, members of oncology multidisciplinary teams rarely systematically analyse their own communication skills. ${ }^{55}$ Improving communication skills in all health care professionals involved in cancer care is of key importance. ${ }^{56}$ The most common communication problems reported by women with breast cancer are difficulty understanding professionals (50\%), difficulty expressing feelings (46\%), desire for more control (45\%) and difficulty asking questions (43\%). ${ }^{57}$ Communication between health care providers and older cancer patients is complicated by the above-mentioned age-related problems, such as cognitive status and sensory impairments, as well as a variety of other factors, such as patients' beliefs, perceptions and knowledge about cancer. ${ }^{58}$ Compared to younger people, older cancer patients ask fewer questions and show less proactive behaviour. Physicians, on the other hand, tend to ask fewer questions and spend less time communicating with older cancer patients. ${ }^{59}$ As unfulfilled information needs influence quality of life more negatively in older compared to younger patients ${ }^{56}$ and the likelihood of effective communication is 
Vries, M. de, Weert, J.C.M. van, Jansen, J., Lemmens, E.P.P., Maas, A.A.M. Step by step development of clinjcal care pathways for older cancer patients: necessary or desirable? European Journal of Cancer: 2007, 43(15), 2170-2178

enhanced when patient-provider communication is aware of the patients' needs, understanding older ceancer patients' information needs becomes essential, and will therefore be discussed below.

A literature review of communication needs in cancer patients of all ages reported a range of unmet needs, and also that patients' needs frequently change over time. A significant proportion of reported unmet needs pertained to unfulfilled needs for disease and treatment-related information, including extent of disease, prognosis, treatment alternatives, treatment intent and side effects.

Physicians have also been found to pay minimal attention to patients' psychosocial concerns ${ }^{60}$ However, older patients tend to prefer information on the most important aspects of the disease and treatment, but are relatively less interested in more detailed information. ${ }^{[61]}$ and ${ }^{[62]}$ Available information concerning agerelated data or information based on specific co-morbidities should be handed over to the patient. [63] and [64]

A study on the needs of patients with colorectal cancer receiving adjuvant chemotherapy indicated that adequate provision of information at times of uncertainty (e.g. at the time of diagnosis, on completion of treatment) may result in the patient reappraising their own coping resources, decreased anxiety and increased adaptation. ${ }^{65}$ Continuous assessment of needs is necessary to ascertain important changes in information needs over time and to accommodate variations in informational preferences. The latter is important as information needs of cancer patients vary considerably across individuals, ${ }^{[4]}$ and [66] ${ }^{6 e i n g}$ even larger in older than in younger patients. A framework for clinical care pathways should define how these needs will be implemented in the care process and how the information will be tailored to the patients' needs.

\section{VARIABILITY IN TREATMENT PLANS}

Physicians seem to apply guidelines or standard treatment regimens less frequently in older cancer patients: In this group of patients, radiotherapy is less frequently applied in most tumour types.

Co-morbidity does not explain the difference. ${ }^{67}$ Elderly patients with stage III colon cancer, small cell lung cancer, ovarian cancer or non-Hodgkin's lymphoma receive (adjuvant) chemotherapy less often. ${ }^{68}$ Physicians may consider patient characteristics (as mentioned above), estimated life-expectancy or, sometimes, a higher complication rate in older patients and therefore deviate from standard regimens applied in younger patients. On the other hand, patient preferences also differ between age groups: chemotherapy naïve cancer patients above 60 years demanded twice as much symptom relief and change survival compared to their younger counterparts to accept chemotherapy. ${ }^{[69]}$ and ${ }^{[70]}$ In other words, compared to younger patients, the present cohort of older patients asks for more benefits or less toxicity to accept chemotherapy. As a result, physician and patient preferences lead to a greater variability in treatment plans in old age groups. Geriatric assessment reveals effect modifiers of the results of oncological treatment. These data are relevant to estimate survival or toxicity but they are not systematically identified by routine oncological assessment. ${ }^{3}$ Clinical care pathways raise the possibility to integrate systematically several assessment techniques and their results in oncological care and subsequently contribute to a reasoned variability of treatment.

\section{CLINICAL CARE PATHWAYS: A KEY TO GOOD CANCER CARE}

In cancer care there is evidence that multidisciplinary teams improve outcomes. ${ }^{71}$ Local organisational structures and processes of care may play an important role in patient treatment and prognosis. ${ }^{72}$ There are often practical barriers that limit successful implementation of multidisciplinary teams. ${ }^{73}$ Also, patient education is a key factor in clinical care pathways for older cancer patients. ${ }^{74}$ Particularly, the information process and preservation of a coherent intervention plan are vulnerable in complex interdisciplinary care. Poor interdisciplinary communication between different specialists and departments adds to the confusion about diagnosis, test results and management. ${ }^{[55] \text { and }[75]}$

Clinical care pathways can differ from the process they manage, e.g. diagnostic processes, interventionprocedures and rehabilitation. Pathways can be disease-specific or process specific. ${ }^{76}$ In older patients there is a complexity determined both by case complexity (e.g. related to a patients multiple diseases and functional status) and care complexity (e.g. related to the presence of multiple health care providers). ${ }^{[77]}$ and

We are developing a framework for clinical care pathways in the elderly that can be applied into a disease specific process of care and adapted to the needs of a specific health care organisation. In our view such a 'geriatric' framework incorporates steps that reveal patients' characteristics (as mentioned above), explicit interdisciplinary consultation and interdisciplinary tuning both on the allocation of tasks as well as on the 
Vries, M. de, Weert, J.C.M. van, Jansen, J., Lemmens, E.P.P., Maas, A.A.M. Step by step development of clinjical care pathways for older cancer patients: necessary or desirable? European Journal of Cancer: 2007,43(15), 2170-2178

information process. Common problems or complications in older patients are described in the franivew (e.g. assessment, interventions on incontinence, confusion state). Furthermore, the framework makes continuity of care explicit including actions to achieve this continuity.

\section{CONCLUSION}

Older cancer patients with complex problems such as sensory deficits, impaired cognitive function and comorbidity, require comprehensive physical and psychosocial support from health care providers. We are developing a framework for clinical care pathways for cancer in elderly patients, in collaboration with national institutes for quality in health care and relevant scientific societies. This framework will be tailored to older patients' specific needs and circumstances. It needs to identify appropriate interventions.

Multidisciplinary evaluations during the continuum of care are essential to achieve optimal tuning and continuity. It also includes (multidisciplinary) guidelines for information-giving and patient education. Team, process and service indicators can be used for evaluation. Given the high incidence and prevalence of colorectal cancer among older people and the high prevalence of co-morbidity and functional problems, developing a 'geriatric' clinical pathway for patients with this cancer would be a good early target.

\section{CONFLICT OF INTEREST STATEMENT}

None declared.

\section{ACKNOWLEDGEMENTS}

We would like to thank the 'Francinus de Windt Foundation' for their grant which enables us to develop the framework as described in this article.

\section{FIGURES AND TABLES}

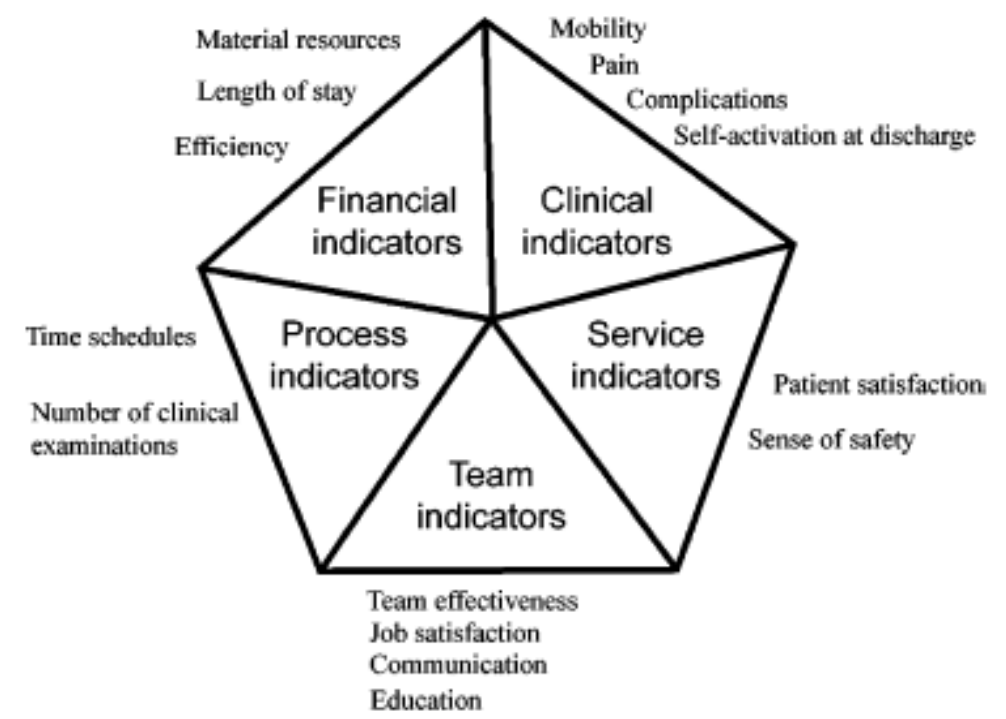

Fig. 1 - Clinical pathway compass. (Source: Van Herck P et al.

Effects of clinical pathways; do they work? J Integr Care

Pathways 2004;8:95-100.) 
Vries, M. de, Weert, J.C.M. van, Jansen, J., Lemmens, E.P.P., Maas, A.A.M. Step by step development of clinjcal care pathways for older cancer patients: necessary or desirable? European Journal of Cancer: 2007,43(15), 2170-2178

\begin{tabular}{|c|c|c|c|c|c|c|c|c|c|}
\hline \multirow[t]{2}{*}{ Problem } & \multicolumn{9}{|c|}{ Implications } \\
\hline & $\begin{array}{l}\text { Decreased } \\
\text { treatment } \\
\text { tolerance/ } \\
\text { increased } \\
\text { complications }\end{array}$ & $\begin{array}{c}\text { Decreased } \\
\text { life-expectancy/ } \\
\text { prognosis }\end{array}$ & $\begin{array}{l}\text { Increased } \\
\text { cognitive } \\
\text { decline }\end{array}$ & $\begin{array}{c}\text { Increased } \\
\text { functional } \\
\text { decline/(I) ADL- } \\
\text { dependence* }\end{array}$ & $\begin{array}{l}\text { Increased } \\
\text { depression* }\end{array}$ & $\begin{array}{c}\text { Decreased } \\
\text { treatment } \\
\text { compliance }\end{array}$ & $\begin{array}{c}\text { Decreased } \\
\text { quality of } \\
\text { life/life-satisfaction }\end{array}$ & $\begin{array}{l}\text { Increased } \\
\text { fear/ } \\
\text { confusion }\end{array}$ & $\begin{array}{c}\text { Decreased } \\
\text { recall/increased } \\
\text { mis-understanding }\end{array}$ \\
\hline Cancer at higher age & 79 & 79 & 41 & $34^{6}$ & $21,31,33$ & & & & \\
\hline Poor health status & & 28 & & 34 & 23,33 & & 33 & & \\
\hline Co-morbidity & 79 & $17,18,34$ & & & & & & & \\
\hline Poly-pharmacy & 20 & & & & & & & & \\
\hline $\begin{array}{l}\text { (Insufficient } \\
\text { attention to) } \\
\text { suditory problems }\end{array}$ & & & $38-40$ & 36 & & 58 & & 58 & $38-90,58$ \\
\hline $\begin{array}{l}\text { (Insufficient } \\
\text { attention to) } \\
\text { visual problems }\end{array}$ & & & $38-40$ & 36 & & 58 & & 58 & $38-90,58$ \\
\hline $\begin{array}{l}\text { Insufficient } \\
\text { social support }\end{array}$ & & 34 & & & 31-33 & & 33 & & \\
\hline $\begin{array}{l}\text { Insufficient } \\
\text { psychosocial } \\
\text { resources }\end{array}$ & & & & & 33 & & 33 & & \\
\hline Malnutrition & 24 & 34 & & & & & & & \\
\hline Cognitue dedine & 41 & 28,34 & & 28 & & 41 & & & 41 \\
\hline $\begin{array}{l}\text { Functional dedine } \rightarrow \\
\text { (d) ADL-dependence }\end{array}$ & $z^{b}, 28^{b}$ & $29,35,2^{6}, 28^{6}$ & & & $28,21^{c}$ & & & & \\
\hline Depression ${ }^{2}$ & & 28,29 & & & & 24,25 & 26,27 & & \\
\hline $\begin{array}{l}\text { a A 'problem' or an 'iv } \\
\text { problem. } \\
\text { b Relationship describ } \\
\text { c Relationship describ }\end{array}$ & $\begin{array}{l}\text { iplication' in italies } \\
\text { didor IADL-depend } \\
\text { d for ADL-depende }\end{array}$ & $\begin{array}{l}\text { indicates that a proble } \\
\text { nce. } \\
\text { nce. }\end{array}$ & & egatively influene & by another $\mathrm{pr}$ & & efore mentioned as 'prob & em' as well as & \\
\hline
\end{tabular}


Vries, M. de, Weert, J.C.M. van, Jansen, J., Lemmens, E.P.P., Maas, A.A.M. Step by step development of clinjcal care pathways for older cancer patients: necessary or desirable? European Journal of Cancer: 2007,43(15), 2170-2178

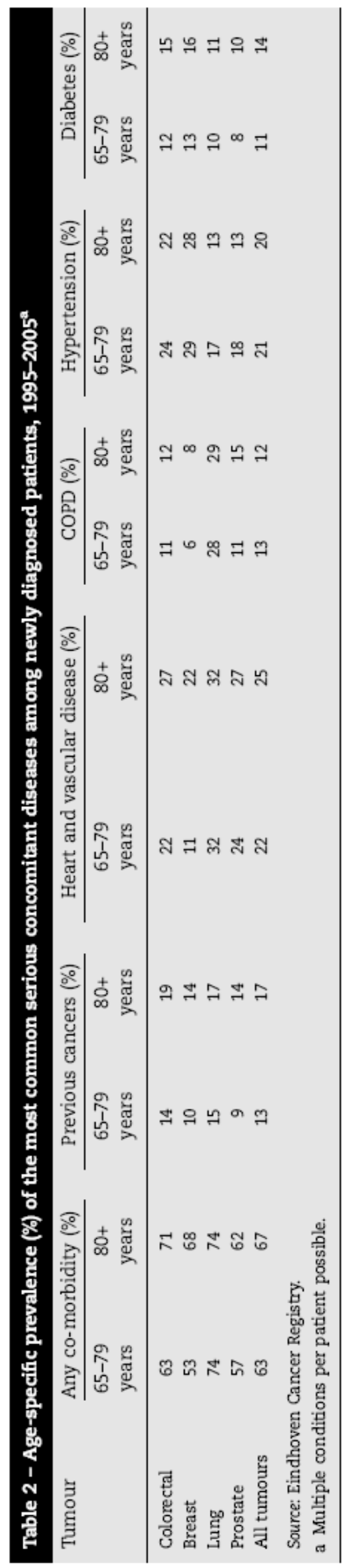


Vries, M. de, Weert, J.C.M. van, Jansen, J., Lemmens, E.P.P., Maas, A.A.M. Step by step development of clinjical care pathways for older cancer patients: necessary or desirable? European Journal of Cancer: 2007, 43(15), 2170-2178

Table 3 - Ten recommendations to improve recall of information in older cancer patients

\begin{tabular}{|c|c|}
\hline 1. & $\begin{array}{l}\text { Encourage older cancer patients to bring a relative with them to the clinic, }{ }^{53,80} \text { check whether the } \\
\text { patient wants this person to be present }{ }^{60}\end{array}$ \\
\hline 2. & Target the information and prioritise to the most important, personally relevant information ${ }^{51}$ \\
\hline 3. & Provide information in a structured manner, categorise and stick to one topic at a time $\mathrm{e}^{49,80}$ \\
\hline 4. & $\begin{array}{l}\text { Detect possibly sensory deficits }{ }^{58} \text { by asking patients to repeat information and/or read aloud text, } \\
\text { minimise visual and auditory distractions } \mathrm{s}^{80}\end{array}$ \\
\hline 5. & Sit face to face with the patient and maintain eye contact ${ }^{80}$ \\
\hline 6. & Encourage patient and relatives to ask questions ${ }^{80}$ \\
\hline 7. & Speak slowly, clearly and loudly and avoid the use of jargon ${ }^{80}$ \\
\hline 8. & Summarise and repeat the most important, personally relevant information ${ }^{49}$ \\
\hline 9. & Combine different methods (oral, written audio-visual) of offering information ${ }^{49,80}$ \\
\hline 10. & Give information at different time points, e.g. preoperatively and re-teach during the days and weeks after surgery ${ }^{47}$ \\
\hline
\end{tabular}

\section{REFERENCES}

1 Z. Chouliara, N. Kearney, D. Stott, A. Molassiotis and M. Miller, Perceptions of older people with cancer of information, decision making and treatment: a systematic review of selected literature, Ann Oncol 15 (2004), pp. 1596-1602.

2 A.M. Colussi, L. Mazzer and D. Candotto et al., The elderly cancer patient: a nursing perspective, Crit

Rev Oncol Hematol 39 (2001), pp. 235-245.

3 H.A.A.M. Maas, M.L.G. Janssen-Heijnen, M.O.R. Olde Rikkert and A.N.M. Wymenga, Comprehensive geriatric assessment and its clinical impact in oncology, Eur J Cancer (2007).

4 L. Blesser de, R. Depreitere, K. Wale de, K. Vanhaecht, J. Vlayen and W. Sermeus, Defining pathways, J

Nurs Manage 14 (2006), pp. 553-563.

5 European Pathway Association.

http://www.sciencedirect.com/science? ob=RedirectURL\& method=externObjLink\& locator=url\& plusSig $\mathrm{n}=\% 2 \mathrm{~B} \&$ targetURL=http\%253A\%252F\%252Fwww.EPA.org.

6 P. van Herck, K. Vanhaeacht and W. Sermeus, Effects of clinical pathways; do they work?, J Integr Care Pathways 8 (2004), pp. 95-100.

7 M. Renholm, H. Leino-Kilpi and T. Suominen, Critical pathways. A systematic review, J Nurs Adm 32 (2002), pp. 196-202.

$8 \mathrm{~W}$. Sermeus and K. Vanhaeacht, What are clinical care pathways? [Wat zijn klinische paden?], Acta Hospitalia 3 (2002), pp. 5-11.

9 M. Panella, S. Marchisio and F. Di Stanislao, Reducing clinical variations with clinical pathways: do pathways work?, Int J Qual Health Care 15 (2003), pp. 509-521.

10 Devriese S, Lambert ML, Eyssen M, et al. The use of clinical care pathways and guidelines to determine physicians' hospital fees prospectively: easier said than done. Brussels: Belgian Healthcare Knowledge Centre (KCE); 2005. KCE reports, vol. 18.

11 C.A. Luhrs, S. Meghani and P. Homel et al., Pilot of a pathway to improve the care of imminently dying oncology inpatients in a Veterans Affairs Medical Center, J Pain Symptom Manage 29 (2005), pp. 544551.

12 K. Ghosh, L.S. Downs and L.A. Padilla et al., The implementation of critical pathways in gynecologic oncology in a managed care setting: a cost analysis, Gynecol Oncol 83 (2001), pp. 378-382.

13 T.J. Smith and B.E. Hillner, Ensuring quality cancer care by the use of clinical practice guidelines and critical pathways, J Clin Oncol 19 (2001), pp. 2886-2897.

$14 \mathrm{M}$. Extermann and A. Hurria, Comprehensive geriatric assessment for older patients with cancer, J Clin Oncol 25 (2007), pp. 1824-1831.

15 M. Extermann, Future of geriatric oncology, Aging Health 3 (2007), pp. 149-158.

16 M.B. Rodin and S.G. Mohile, A practical approach to geriatric assessment in oncology, J Clin Oncol 25 (2007), pp. 1936-1944.

17 I. Carreca, L. Balducci and M. Extermann, Cancer in the older person, Cancer Treat Rev 31 (2005), pp. 380-402.

18 S.M. Lichtman, Guidelines for the treatment of elderly cancer patients, Cancer Control 10 (2003), pp. 445-453.

19 M. Extermann, Interaction between comorbidity and cancer, Cancer Control 14 (2007), pp. 13-22.

20 A.N. Wymenga, J.P. Slaets and D.T. Sleijfer, Treatment of cancer in old age, shortcomings and challenges, Neth J Med 59 (2001), pp. 259-266. 
Vries, M. de, Weert, J.C.M. van, Jansen, J., Lemmens, E.P.P., Maas, A.A.M. Step by step development of clinjcal care pathways for older cancer patients: necessary or desirable? European Journal of Cancer: 2007,43(15), 2170-2178

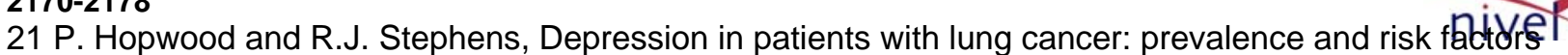
derived from quality-of-life data, J Clin Oncol 18 (2000), pp. 893-903.

22 A.T. Beekman, B.W. Penninx, D.J. Deeg, E. de Beurs, S.W. Geerling and W. van Tilburg, The impact of depression on the well-being, disability and use of services in older adults: a longitudinal perspective, Acta Psychiatr Scand 105 (2002), pp. 20-27.

23 E. Bohlmeijer, F. Smith, C. Smits and P. Cuijpers, Integral approach of prevention of depression in the elderly [Integral aanpak depressiepreventie bij ouderen], Trimbos Instituut, Utrecht (2005).

$24 \mathrm{~L}$. Balducci and M. Extermann, Management of cancer in the older person: a practical approach, Oncologist 5 (2005), pp. 224-237.

25 M.R. DiMatteo, H.S. Lepper and T.W. Croghan, Depression is a risk factor for noncompliance with medical treatment: meta-analysis of the effects of anxiety and depression on patient adherence, Arch Intern Med 160 (2000), pp. 2101-2107.

26 M.R. Visser and E.M. Smets, Fatigue, depression and quality of life in cancer patients: how are they related?, Support Care Cancer 6 (1998), pp. 101-108.

27 J. Skarstein, N. Aass, S.D. Fossa, E. Skovlund and A.A. Dahl, Anxiety and depression in cancer patients: relation between the Hospital Anxiety and Depression Scale and the European Organization for Research and Treatment of Cancer Core Quality of Life Questionnaire, J Psychosom Res 49 (2000), pp. 27-34.

28 L. Balducci, Evidence-based management of cancer in the elderly, Cancer Control 7 (2000), pp. 368376.

29 M. Stommel, B.A. Given and C.W. Given, Depression and functional status as predictors of death among cancer patients, Cancer 94 (2002), pp. 2719-2727.

30 S.D. Passik, W. Dugan, M.V. McDonald, B. Rosenfeld, D.E. Theobald and S. Edgerton, Oncologists' recognition of depression in their patients with cancer, J Clin Oncol 16 (1998), pp. 1594-1600.

31 D.M. Hann, T.E. Oxman, T.A. Ahles, C.T. Furstenberg and T.A. Stuke, Social support adequacy and depression in older patients with metastatic cancer, Psycho-Oncology 4 (1995), pp. 213-221.

32 M.J. Prince, R.H. Harwood, R.A. Blizard, A. Thomas and A.H. Mann, Social support deficits, loneliness and life events as risk factors for depression in old age. The Gospel Oak Project VI, Psychol Med 27 (1997), pp. 323-332.

33 E.A. Perkins, B.J. Small, L. Balducci, M. Extermann, C. Robb and W.E. Haley, Individual differences in well-being in older breast cancer survivors, Crit Rev Oncol Hematol 62 (2007), pp. 74-83.

34 D. Serraino, L. Fratino and V. Zagonel, Prevalence of functional disability among elderly patients with cancer, Crit Rev Oncol Hematol 39 (2001), pp. 269-273.

35 L. Balducci, New paradigms for treating elderly patients with cancer: the comprehensive geriatric assessment and guidelines for supportive care, J Support Oncol 1 (2003), pp. 30-37.

36 B.K. Keller, J.L. Morton, V.S. Thomas and J.F. Potter, The effect of visual and hearing impairments on functional status, J Am Geriatr Soc 47 (1990), pp. 1319-1325.

37 J. Close, M. Ellis, R. Hooper, E. Glucksman, S. Jackson and C. Swift, Prevention of falls in the elderly trial (PROFET): a randomised controlled trial, Lancet 353 (1999), pp. 93-97.

38 P.B. Baltes and U. Lindenberger, Emergence of a powerful connection between sensory and cognitive functions across the adult life span: a new window to the study of cognitive aging?, Psychol Aging 12 (1997), pp. 12-21.

39 M.P. van Boxtel, C.E. van Beijsterveldt, P.J. Houx, L.J. Anteunis, J.F. Metsemakers and J. Jolles, Mild hearing impairment can reduce verbal memory performance in a healthy adult population, $\mathrm{J}$ Clin Exp Neuropsychol 22 (2000), pp. 147-154.

40 S.A. Valentijn, M.P. van Boxtel and S.A. van Hooren et al., Change in sensory functioning predicts change in cognitive functioning: results from a 6-year follow-up in the Maastricht aging study, J Am Geriatr Soc 53 (2005), pp. 374-380.

41 S.C. Brown and D.C. Park, Theoretical models of cognitive aging and implications for translational research in medicine, Gerontologist 43 (Spec No. 1) (2003), pp. 57-67.

42 C. Jonker, M.I. Geerlings and B. Schmand, Are memory complaints predictive for dementia? A review of clinical and population-based studies, Int J Geriatr Psychiatry 15 (2000), pp. 983-991.

43 T.A. Salthouse, The processing-speed theory of adult age differences in cognition, Psychol Rev 103 (1996), pp. 403-428.

44 R. Zacks and L. Hasher, Cognitive gerontology and attentional inhibition: a reply to Burke and McDowd, J Gerontol B 52 (1997), pp. P274-P283.

45 J.B. Halter, The challenge of communicating health information to elderly patients: a view from geriatric medicine. In: D.C. Park, R.W. Morrel and K. Shifren, Editors, Processing of medical information in aging patients: cognitive and human factors perspectives, Erlbaum, Mahwah (NJ) (1999), pp. 23-28.

46 S. Snelgrove, A consideration of memory in relation to information giving, Nurs Times 102 (2006), pp. 26-28. 
Vries, M. de, Weert, J.C.M. van, Jansen, J., Lemmens, E.P.P., Maas, A.A.M. Step by step development of clinjcal care pathways for older cancer patients: necessary or desirable? European Journal of Cancer: 2007,43(15), 2170-2178

47 T.B. Sahay, R.E. Gray and M. Fitch, A qualitative study of patient perspectives on colorectal candider, Cancer Pract 8 (2000), pp. 38-44.

$48 \mathrm{~J} . \mathrm{H}$. Chelf, P. Agre and A. Axelrod et al., Cancer-related patient education: an overview of the last decade of evaluation and research, Oncol Nurs Forum 28 (2001), pp. 1139-1147.

49 R.P. Kessels, Patients' memory for medical information, J R Soc Med 96 (2003), pp. 219-222.

50 Jansen J, van Weert JCM, van der Meulen N, Van Dulmen S, Heeren T, Bensing J. Recall in older cancer patients: measuring memory for medical information. Gerontologist [in press].

51 D.G. Morrow, M. Weiner, J. Young, D. Steinley, M. Deer and M.D. Murray, Improving medication knowledge among older adults with heart failure: a patient-centered approach to instruction design, Gerontologist 45 (2005), pp. 545-552.

52 J. Kerr, J. Engel, A. Schlesinger-Raab, H. Sauer and D. Holzel, Communication, quality of life and age: results of a 5-year prospective study in breast cancer patients, Ann Oncol 14 (2003), pp. 421-427.

53 W. Liang, C.B. Burnett and J.H. Rowland et al., Communication between physicians and older women with localized breast cancer: implications for treatment and patient satisfaction, J Clin Oncol 20 (2002), pp. 1008-1016.

54 M.E. Mills and R. Davidson, Cancer patients' sources of information: use and quality issues, Psychooncology 11 (2002), pp. 371-378.

$55 \mathrm{~L}$. Fallowfield and V. Jenkins, Effective communication skills are the key to good cancer care, Eur J Cancer 35 (1999), pp. 1592-1597.

56 P. Maguire, Improving communication with cancer patients, Eur J Cancer 35 (1999), pp. 2058-2065.

57 R. Zachariae, C.G. Pedersen, A.B. Jensen, E. Ehrnrooth, P.B. Rossen and H. von der Maase, Association of perceived physician communication style with patient satisfaction, distress, cancer-related self-efficacy, and perceived control over the disease, $\mathrm{Br}$ J Cancer 88 (2003), pp. 658-665.

58 M.G. Greene and R.D. Adelman, Physician-older patient communication about cancer, Patient Educ Couns 50 (2003), pp. 55-60.

59 L.A. Siminoff, G.C. Graham and N.H. Gordon, Cancer communication patterns and the influence of patient characteristics: disparities in information-giving and affective behaviors, Patient Educ Couns 62 (2006), pp. 355-360.

60 T.F. Hack, L.F. Degner and P.A. Parker, The communication goals and needs of cancer patients: a review, Psychooncology 14 (2005), pp. 831-845 [discussion 846-7].

61 J. Jansen, J. van Weert, S. van Dulmen, T. Heeren and J. Bensing, Patient Education about treatment in cancer care. An overview of the literature on older patients' needs, Cancer Nurs 30 (2007), pp. 160-251.

$62 \mathrm{~K}$. Ankem, Factors influencing information needs among cancer patients: a meta-analysis, Libr Inf Sci Res 28 (2006), pp. 7-23.

63 M.A. Shahir, V.E. Lemmens, L.V. van de Poll-Franse, A.C. Voogd, H. Martijn and M.L. Janssen-Heijnen, Elderly patients with rectal cancer have a higher risk of treatment-related complications and a poorer prognosis than younger patients: a population-based study, Eur J Cancer 42 (2006), pp. 3015-3021.

64 L.V. van de Poll-Franse, S. Houterman, M.L. Janssen-Heijnen, M.W. Dercksen, J.W. Coebergh and H.R. Haak, Less aggressive treatment and worse overall survival in cancer patients with diabetes: a large population based analysis, Int J Cancer 120 (2007), pp. 1986-1992.

$65 \mathrm{G}$. Knowles, A. Tierney, D. Jodrell and A. Cull, The perceived information needs of patients receiving adjuvant chemotherapy for surgically resected colorectal cancer, Eur J Oncol Nurs 3 (1999), pp. 208-220.

$66 \mathrm{~B}$. van der Molen, Relating information needs to the cancer experience: 1 . Information as a key coping strategy, Eur J Cancer Care (Engl) 8 (1999), pp. 238-244.

67 A.J. Vulto, V.E. Lemmens and M.W. Louwman et al., The influence of age and comorbidity on receiving radiotherapy as part of primary treatment for cancer in South Netherlands, 1995 to 2002, Cancer 106 (2006), pp. 2734-2742.

68 M.L. Janssen-Heijnen, S. Houterman, V.E. Lemmens, M.W. Louwman, H.A. Maas and J.W. Coebergh, Prognostic impact of increasing age and co-morbidity in cancer patients: a population-based approach, Crit Rev Oncol Hematol 55 (2005), pp. 231-240.

69 R.M. Bremnes, K. Andersen and E.A. Wist, Cancer patients, doctors and nurses vary in their willingness to undertake cancer chemotherapy, Eur J Cancer 31A (1995), pp. 1955-1959.

70 G. Silvestri, R. Pritchard and H.G. Welch, Preferences for chemotherapy in patients with advanced nonsmall cell lung cancer: descriptive study based on scripted interviews, BMJ 317 (1998), pp. 771-775.

71 E. Morris, R.A. Haward, M.S. Gilthorpe, C. Craigs and D. Forman, The impact of the Calman-Hine report on the processes and outcomes of care for Yorkshire's colorectal cancer patients, $\mathrm{Br} \mathrm{J}$ Cancer 95 (2006), pp. 979-985.

72 A. Govindarajan, N.G. Coburn, A. Kiss, L. Rabeneck, A.J. Smith and C.H. Law, Population-based assessment of the surgical management of locally advanced colorectal cancer, J Natl Cancer Inst 98 (2006), pp. 1474-1481.

73 A. Fleissig, V. Jenkins, S. Catt and L. Fallowfield, Multidisciplinary teams in cancer care: are they effective in the UK?, Lancet Oncol 7 (2006), pp. 935-943. 
Vries, M. de, Weert, J.C.M. van, Jansen, J., Lemmens, E.P.P., Maas, A.A.M. Step by step development of clinjcal care pathways for older cancer patients: necessary or desirable? European Journal of Cancer: 2007,43(15), 2170-2178

74 D.W. Keetch and D. Buback, A clinical-care pathway for decreasing hospital stay after radical prostatectomy, Br J Urol 81 (1998), pp. 398-402.

75 J. van Weert, S. van Dulmen, P. Bar and E. Venus, Interdisciplinary preoperative patient education in cardiac surgery, Patient Educ Couns 49 (2003), pp. 105-114.

76 S.G. Edwards, A.J. Thompson and E.D. Playford, Integrated care pathways: disease-specific or process-specific?, Clin Med 4 (2004), pp. 132-135.

77 P. de Jonge, F.J. Huyse and F.C. Stiefel, Case and care complexity in the medically ill, Med Clin North Am 90 (2006), pp. 679-692.

78 F.J. Huyse, P. de Jonge and J.P. Slaets et al., COMPRI - an instrument to detect patients with complex care needs: results from a European study, Psychosomatics 42 (2001), pp. 222-228.

79 V.E. Lemmens, M.L. Janssen-Heijnen, C.D. Verheij, S. Houterman, O.J. Repelaer van Driel and J.W. Coebergh, Co-morbidity leads to altered treatment and worse survival of elderly patients with colorectal cancer, Br J Surg 92 (2005), pp. 615-623.

80 T.E. Robinson 2nd, G.L. White Jr. and J.C. Houchins, Improving communication with older patients: tips from the literature, Fam Pract Manage 13 (2006), pp. 73-78. 